\title{
A Fatal Case of Intra-Abdominal Hemorrhage Following Diagnostic Blind Percutaneous Liver Biopsy in a Patient With Peliosis Hepatis
}

\author{
Saptarshi Biswas ${ }^{\mathrm{a}, \mathrm{c}}$, Shekhar Gogna ${ }^{\mathrm{b}}$, Prem Patel ${ }^{\mathrm{b}}$
}

\begin{abstract}
Peliosis hepatis $(\mathrm{PH})$ is a rare vascular condition of the liver characterized by the presence of cystic blood filled cavities distributed randomly throughout the liver parenchyma. We describe a case of a 42-year-old previously healthy male patient, airlifted to us in a state of hemorrhagic shock after undergoing percutaneous diagnostic liver biopsy for lesions seen on CT scan. Repeat CT scan with IV contrast on presentation in our hospital showed intraperitoneal bleeding. Hepatic angiography failed to identify any specific bleeding source. A diagnostic laparoscopy was performed and approximate 9 L of hemoperitoneum was evacuated. The postoperative course was complicated with rapid hemodynamic deterioration, associated with acute hepatic failure progressively leading to multiorgan failure and death in spite of aggressive intensive care support. We suggest that PH should be considered as differential diagnosis of hypervascular hepatic lesions. It potentially can cause fatal acute non-traumatic liver hemorrhage.
\end{abstract}

Keywords: Peliosis hepatis; Hemoperitoneum; Blind percutaneous liver biopsy

\section{Introduction}

The term peliosis hepatis $(\mathrm{PH})$ originates from the Greek "pelios" which means "lead-colored" (extravasated blood). It is a disease characterized by multiple, small, blood-filled cysts within the parenchymatous organs. These cysts communicate with the hepatic sinusoids and are associated with rupture of the reticulin framework [1].

Patient with PH may come to the attention just after the

Manuscript submitted May 28, 2017, accepted July 3, 2017

aDepartment of Trauma and Acute Care Surgery, Forbes Hospital, Allegheny Health Network, PA 15146, USA

bDepartment of General Surgery, Westchester University Medical Center, Valhalla, NY, USA

${ }^{\mathrm{c} C}$ Corresponding Author: Saptarshi Biswas, Department of Trauma and Acute Care Surgery, Forbes Hospital, Allegheny Health Network, PA 15146, USA.

Email: saptarshibiswas@comcast.net

doi: https://doi.org/10.14740/gr873e rupture, either spontaneous or any manipulation radiologically or surgically resulting in a massive hemoperitoneum. We describe a case of a previously health young male patient who developed hemoperitoneum and progressive hepatic decompensation leading to multiorgan failure following a diagnostic blind percutaneous liver biopsy.

\section{Case Report}

A 42-year-old male with no significant past medical or surgical history was admitted at an outside hospital after he complained of pain abdomen and mild elevation of hepatic function panels. He underwent ultrasonography (USG) at another hospital which showed hypoechoic lesions; for further characterization, CT scan was done which showed multiple low attenuation areas in the liver. CT-guided biopsies were attempted. Patient's $\mathrm{Hb}$ and Hct gradually started to drop and he required blood transfusions at another hospital. His $\mathrm{Hb}$ drifted down to $10.2 \mathrm{mg} / \mathrm{dL}$ from its initial value of $14 \mathrm{mg} / \mathrm{dL}$, although his liver function tests (LFTs) remained unchanged. He however did receive transfusion of packed RBCs due to acute drop in $\mathrm{Hb}$ and Hct following the biopsy.

The patient was subsequently transferred to the hepatopancreaticobiliary (HPB) surgery service for further management at our hospital.

At the time of admission, the patient complained of right upper quadrant discomfort and pain. No nausea, vomiting, diarrhea, fever, chills, and cough were documented at that time. However, physical examinations revealed that he was hypotensive with tachycardia. The vitals were recorded with blood pressure (BP) of $80 / 30 \mathrm{~mm} \mathrm{Hg}$, and pulse rate of 110 beats/ min. Abdomen was grossly soft with no obvious guarding or rigidity was noted. He did have tenderness in his right upper quadrant on deep palpation. Respiratory examination was clear to auscultation bilaterally. Cardiovascular examination showed S1, S2 heart sounds audible with no murmurs, gallops or rubs heard. At presentation, his lab values were as follows: $\mathrm{Hb} 9.6 \mathrm{mg} / \mathrm{dL}$ (13 - $18 \mathrm{mg} / \mathrm{dL}$ ), Hct 28\% (40-53\%), platelets $139 \times 10^{9} / \mathrm{L}\left(150-400 \times 10^{9} / \mathrm{L}\right)$, SGOT $30 \mathrm{IU} / \mathrm{L}(5-30 \mathrm{IU} / \mathrm{L})$, SGPT 19 IU/L (5 - 30 IU/L), GGT 153 U/L (6 - 50 U/L), SAP $195 \mathrm{U} / \mathrm{L}(50-100 \mathrm{U} / \mathrm{L})$, total bilirubin $5 \mathrm{mg} / \mathrm{dL}$, and serum ammonia $60 \mu \mathrm{g} / \mathrm{dL}$. His coagulation parameters were as follows: PT 12.5 s (11 - 14 s), INR 1.14, PTT 44.3 s (20 - 40 s), and fibrinogen $420 \mathrm{mg} / \mathrm{dL}(180-400 \mathrm{mg} / \mathrm{dL})$. 


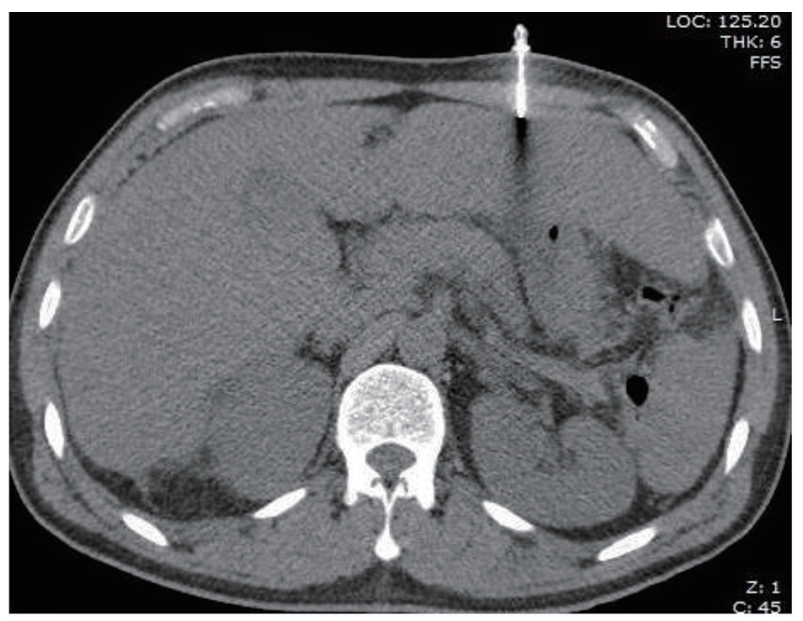

Figure 1. CT scan showing suspected mass in segment $6 / 7$ and left lobe.

The patient was managed conservatively with supportive measures in the SICU. Serial Hb and Hct were ordered. The patient did not require any transfusions of blood products during his ICU stay and his parameters remained steady.

Patient was shifted to the surgical floor and as part of diagnostic workup, CT of abdomen and pelvis was performed which showed a heterogeneous mass measuring $10.6 \times 11.4$ $\mathrm{cm}$ involving segments 6 and 7 of the liver. This mass was suspected to be tumor deposit. There was high density fluid layering in right paracolic gutter suspicious of hemoperitoneum (Fig. 1). MRI showed innumerable T2 hyperintense nodules throughout the liver with delayed enhancement, and large T2 hyperintense lesion in segments VI and VII containing multiple smaller lesions with delayed enhancement (Fig. 2).

CT-guided liver biopsy was reattempted under anesthesia. The tissue on histopathological examination had liver architecture with vascular lacunae (Fig. 3). The patient had severe abdominal distention causing respiratory distress after 2 days of liver biopsy. He was moved to ICU and patient then underwent hepatic angiogram to evaluate for bleeding. There was no definite source of bleeding that could be identified. The patient

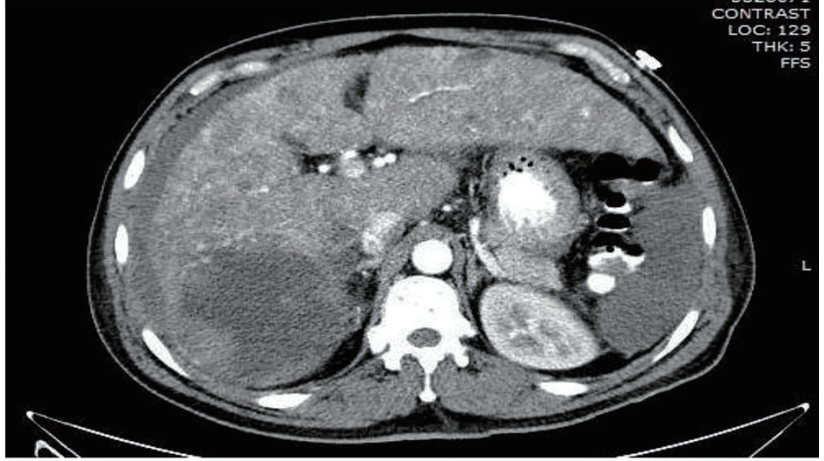

Figure 2. MRI liver showing T2 hyperintense nodules throughout the liver with delayed enhancement, and large T2 hyperintense lesion in segments $\mathrm{VI}$ and $\mathrm{VII}$ containing multiple smaller lesions with delayed enhancement.

was taken to the operating room and diagnostic laparoscopy was done with drainage of about 9 L of bloody fluid; intra-operatively, the liver appeared diseased and fragile consisting of vascular cavities consistent with peliosis hepatis. The patient tolerated the procedure well and was extubated postoperatively.

He continued to have distention of the abdomen. Patient's condition worsened secondary to progressive abdominal distention and respiratory distress. He was hypotensive, tachycardia with marginal urine out. His labs were as follows: $\mathrm{Hb}$ $8.1 \mathrm{mg} / \mathrm{dL}(13-18 \mathrm{mg} / \mathrm{dL})$, Hct $24 \%$ (40-53\%), platelets $49 \times$ $10^{9} / \mathrm{L}\left(150-400 \times 10^{9} / \mathrm{L}\right)$, SGOT $1,180 \mathrm{IU} / \mathrm{L}(5-30 \mathrm{IU} / \mathrm{L})$, SGPT 440 IU/L ( 5 - 30 IU/L), GGT 210 U/L (6 - 50 U/L), SAP $440 \mathrm{U} / \mathrm{L}(50-100 \mathrm{U} / \mathrm{L})$, total bilirubin $37.2 \mathrm{mg} / \mathrm{dL}$, and serum ammonia $86 \mu \mathrm{g} / \mathrm{dL}$ and coagulation parameters were PT 20.9 s (11 - 14 s), INR 1.94, PTT 58 s (20 - 40 s), and fibrinogen $110 \mathrm{mg} / \mathrm{dL}(180-400 \mathrm{mg} / \mathrm{dL})$. He was put on epinephrine, norepinephrine and vasopressin drips and continuous albumin infusion. Despite all resuscitative measures, his serum lactate worsened from 2.0 to $6.5 \mathrm{mmol} / \mathrm{L}$.

After multimodality board meeting, it was decided that patient required liver transplant as the liver function continued to deteriorate. He was placed on UNOS list. The patient required endotracheal intubation and hemodynamics support

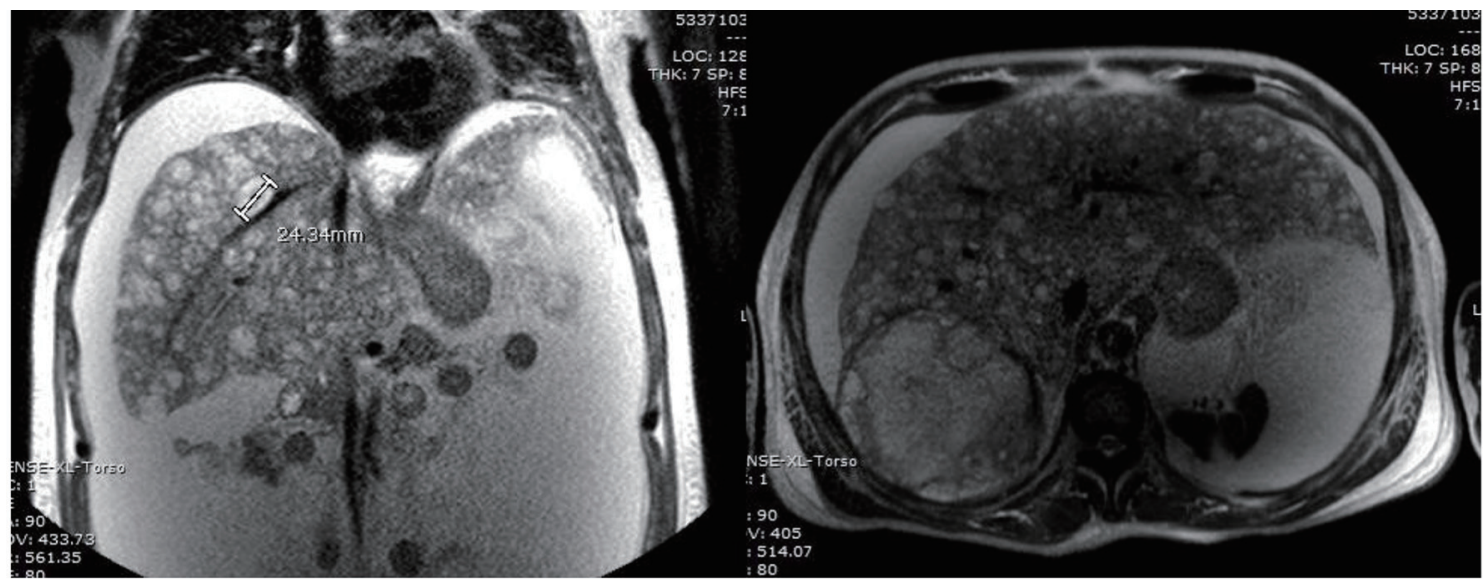

Figure 3. Needle biopsy being performed through left lobe in $\mathrm{OSH}$. 
in the form of inotropes in the ICU. During the course of the treatment, the healthcare proxy and the family were updated regularly. Family decided to withdraw care. The patient was put into comfort care, and the patient expired on the 10th day after biopsy.

\section{Discussion}

$\mathrm{PH}$ is a rare vascular condition of the liver characterized by the presence of cystic blood filled cavities distributed randomly throughout the liver parenchyma. PH was first described in 1861 by Wagner [2] and named by Schoenlank in 1916 [3].

Pathogenesis of PH is not completely understood. However literature is replete with multiple hypotheses. The common mechanism that most of studies seem to agree is the loss of the integrity of the microvasculature leading to microcirculatory disturbances. This in turn alters the local intravascular pressure conditions causing direct damage to the sinusoidal lining cells $[1,3,4]$. Sinusoidal obstruction, hepatocellular necrosis and injury directly to the sinusoidal barriers are the postulated mechanisms especially in adult patients [5]. Yanoff and Rawson [6] have described two primary morphological patterns: parenchymal pattern and phlebectatic pattern. The former is characterized by multiple irregular blood filled spaces, where the endothelial lining is replaced by fibrous tissue. They are associated with multiple areas of focal necrosis. The phlebectatic pattern on the other hand is lined by endothelial cells and communicates with the hepatic sinusoids.

Zak [3] opined these two morphological patterns to be one process initiated by focal necrosis of hepatic parenchyma. Increased endothelial cell permeability with multiple RBCs in the space of Disse [7] supports the fact that toxic substances may induce peliosis. Degott et al [8] reported long-term use of azathioprine can cause fibrous thickening of the hepatic venules leading to PH. Eising et al [9] reported an increased incidence of hepatic rupture following blunt trauma in patients with $\mathrm{PH}$.

Etiology can be divided into three categories broadly: drug/medication, autoimmune diseases and malignancy, and infection $[10,11]$. Drugs associated with $\mathrm{PH}$ are anabolic steroids, azathioprine [12], 6-mercaptopurine [13], 6-thioguanine, cisplatin and oral contraceptives [14]. Toxins (polyvinyl chloride, arsenic, and thorium oxide), autoimmune disease and malignancies such as leukemias, lymphomas, vasculitis, malignant histiocytosis, multiple myeloma, Waldenstrom macroglobulinemia, and Sjogren's syndrome have been linked to $\mathrm{PH}$ in literature. Infectious pathologies consistently associated with PH are human immuno-deficiency virus, tuberculosis, leprosy and Bartonellosis (B. henselae and B. quintana).

Most patients with $\mathrm{PH}$ are asymptomatic and remain undiagnosed or have slowly progressive disease. $\mathrm{PH}$ is often an incidental finding on imaging, or it can present as hepatomegaly, portal hypertension, liver failure $[15,16]$ or unfortunately as intra-abdominal catastrophe due to fatal hemorrhage just as in our patient.

Although often attributed to a systemic etiology, the hepatic distribution in most cases is usually the right lobe. In ad- dition, case reports suggest right lobe predilection in cases of liver rupture in PH [17]. However, Adam et al [18] and Toth et al [19] reported PH cases with left lobe of liver rupture. Some authors have postulated that $\mathrm{PH}$ is a pathology starting with one lobe and progressively involving the whole liver, often leading to hepatic rupture.

The diagnosis of $\mathrm{PH}$ is based on liver imaging and pathological confirmation. Imaging study provides the nature of space occupying lesions. However, the diagnosis can often be missed or delayed as radiological imaging simulates neoplasm or multiple abscesses. The USG shows hypoechoic areas within the liver with intraperitoneal bleeding. Doppler signals are usually normal [20]. On CT scan, the lesions appear as heterogeneous densities that are hypodense on the arterial and venous phase [21]. On imaging studies, the differential diagnosis for PH includes adenoma, hemangioma, focal nodular hyperplasia, abscess, hypervascular metastatic lesions, and hepatocellular carcinoma.

MRI finding is innumerable T2 hyperintense nodules throughout the liver with delayed enhancement. Large T2 hyperintense lesion in segments VI and VII containing multiple smaller lesions with delayed enhancement was seen in our patient (Fig. 3).

Angiography shows multiple small accumulation of contrast dyes especially in the late arterial phase. The enhancement of the peliotic lesions is more prominent during the parenchymal phase which persists into the portal venous phase.

Liver biopsy has been mentioned as a reliable tool in diagnosing $\mathrm{PH}[3,22]$. The differential diagnosis on microscopic examination of liver specimens includes sinusoidal obstruction syndrome, heart failure, and Budd-Chiari syndrome [23]. However, even with USG guidance, percutaneous biopsy has a significant risk of life-threatening hemorrhage. With our experience with this pathology and after review of relevant literature, we would recommend blind percutaneous biopsy only in cases with focal disease. Our patient had generalized disease with most of the vascular cavities more than $1-1.5 \mathrm{~cm}$. There are studies showing that the size of the peliotic cavity and extent of liver involvement appear to be predictive of the clinical manifestations and outcomes of the intervention [12].

No definitive treatment has been identified yet besides removal of causative agents. Erythromycin is the first-line antibiotic therapy for the treatment of angioproliferative lesion due to Bartonella infection [24]. Angiography with embolization has been successfully used to treat bleeding pleliotic cavities [25]. Angiography in our patient however failed to identify source of bleeding. Successful anatomic/non-anatomic wedge resections of the liver have been performed to achieve hemostasis and to obtain the ultimate cure [26]. Liver transplant is also a potential option for $\mathrm{PH}$. Our patient developed acute progressive liver failure after massive intraperitoneal bleed and rapidly decompensated and unfortunately succumbed to the disease when the family decided to withdraw care.

\section{Conclusion}

$\mathrm{PH}$ is a rare vascular condition of the liver characterized by the presence of cystic blood filled cavities distributed throughout 
the liver parenchyma. Causative factor remains largely unknown; however, infection, drugs or autoimmune disease have been implicated. PH is typically asymptomatic or it can present as portal hypertension, cirrhosis or massive intra-abdominal bleeding. Imaging and liver biopsy are most reliable tools in diagnosing. Blind percutaneous biopsy however proved to be fatal in this case. Treatment is supportive and involves removal of the suspected causal agent, angiographic embolization, liver resection and transplant.

\section{Conflicts of Interest}

None.

\section{Funding}

None.

\section{References}

1. Tsokos M, Erbersdobler A. Pathology of peliosis. Forensic Sci Int. 2005;149(1):25-33.

2. Wagner E. Fall von Blutcysten der Leber. Arch d Heilk. 1861;2:369-363.

3. Zak FG. Peliosis hepatis. Am J Pathol. 1950;26(1):1-15, incl 12 pl.

4. Yu CY, Chang LC, Chen LW, Lee TS, Chien RN, Hsieh MF, Chiang KC. Peliosis hepatis complicated by portal hypertension following renal transplantation. World J Gastroenterol. 2014;20(9):2420-2425.

5. Verswijvel G, Janssens F, Colla P, Mampaey S, Verhelst H, Van Eycken P, Erven W. Peliosis hepatis presenting as a multifocal hepatic pseudotumor: MR findings in two cases. Eur Radiol. 2003;13(Suppl 6):L40-44.

6. Yanoff M, Rawson AJ. Peliosis Hepatis. An anatomic study with demonstration of two varieties. Arch Pathol. 1964;77:159-165.

7. Zafrani ES, Cazier A, Baudelot AM, Feldmann G. Ultrastructural lesions of the liver in human peliosis. A report of 12 cases. Am J Pathol. 1984;114(3):349-359.

8. Degott C, Rueff B, Kreis H, Duboust A, Potet F, Benhamou JP. Peliosis hepatis in recipients of renal transplants. Gut. 1978;19(8):748-753.

9. Eising EG, Auffermann W, Peters PE, Schmidt H, Ullrich $\mathrm{K}$. [Focal peliosis of the adult liver in combination with glycogenosis type I (v.Gierke). A case report and review of the recent literature]. Radiologe. 1990;30(9):428-432.

10. Wanless IR, Huang WY. Vascular disorders. In: MacSween's pathology of the liver. 6th ed. New York: Elsevier, 2012: 618-619.

11. Pan W, Hong HJ, Chen YL, Han SH, Zheng CY. Surgical treatment of a patient with peliosis hepatis: a case report.
World J Gastroenterol. 2013;19(16):2578-2582.

12. Cavalcanti R, Pol S, Carnot F, Campos H, Degott C, Driss F, Legendre C, et al. Impact and evolution of peliosis hepatis in renal transplant recipients. Transplantation. 1994;58(3):315-316.

13. Larrey D, Freneaux E, Berson A, Babany G, Degott C, Valla D, Pessayre D, et al. Peliosis hepatis induced by 6-thioguanine administration. Gut. 1988;29(9):12651269.

14. Omori H, Asahi H, Irinoda T, Takahashi M, Kato K, Saito K. Peliosis hepatis during postpartum period: successful embolization of hepatic artery. J Gastroenterol. 2004;39(2):168-171.

15. Atila K, Coker A, Ucar D, Karademir S, Sagol O, Astarcioglu H, Astarcioglu I. A rare clinical entity misdiagnosed as a tumor: peliosis hepatis. Ulus Travma Acil Cerrahi Derg. 2007;13(2):149-153.

16. Khadilkar UN, Prabhu S, Sharma D. Peliosis hepatis presenting as hemoperitoneum. Indian J Med Sci. 2008;62(6):236-237.

17. Choi SK, Jin JS, Cho SG, Choi SJ, Kim CS, Choe YM, Lee KY. Spontaneous liver rupture in a patient with peliosis hepatis: a case report. World J Gastroenterol. 2009; 15(43):5493-5497.

18. Adam G, Lesser T, Neumann R. [Liver rupture in peliosis hepatis]. Zentralbl Chir. 1991;116(6):399-403.

19. Toth P, Takacs I, Kerekes L, Sapy P. [Surgical treatment of intraabdominal hemorrhage in peliosis hepatis]. Chirurg. 2002;73(1):83-85.

20. Kleinig P, Davies RP, Maddern G, Kew J. Peliosis hepatis: central "fast surge" ultrasound enhancement and multislice CT appearances. Clin Radiol. 2003;58(12):995998.

21. Venkatesh SK, Chandan V, Roberts LR. Liver masses: a clinical, radiologic, and pathologic perspective. Clin Gastroenterol Hepatol. 2014;12(9):1414-1429.

22. Zafrani ES, von Pinaudeau Y, Dhumeaux D. Druginduced vascular lesions of the liver. Arch Intern Med. 1983;143(3):495-502.

23. Iwai M, Muramatsu A, Tanaka S, Morikawa T, Mori T, Harada Y, Okanoue T, et al. Macroscopic and microscopic findings of livers in malignant hematologic disorders, biopsied under peritoneoscopy. J Clin Gastroenterol. 2002;35(3):262-265.

24. Perez-Martinez L, Blanco JR, Oteo JA. [Treatment of human infections caused by Bartonella spp.]. Rev Esp Quimioter. 2010;23(3):109-114.

25. Oriordan K, Blei A, Vogelzang R, Nemcek A, Abecassis M. Peliosis hepatis with intrahepatic hemorrhage: successful embolization of the hepatic artery. HPB Surg. 2000;11(5):353-358.

26. Veguillas Redondo P, Ramia Angel JM, Kuhnhart Barrantes A, Cobos Mateos JM, Garcia-Parreno J. Ruptured liver caused by peliosis hepatis. Cir Esp. 2014;92(7):499501. 